
\title{
BReserch S Suare \\ Endosomal acidification inhibitors broadly inhibit influenza virus and coronavirus in vivo
}

\section{Hanjun Zhao}

The University of Hong Kong

\section{Hoiyan Lam}

The University of Hong Kong

\section{Xinxin Zhou}

The University of Hong Kong

\section{Zheng Peng}

The University of Hong Kong

\section{Jasper Chan}

The University of Hong Kong https://orcid.org/0000-0001-6336-6657

\section{Ko-Yung Sit}

The University of Hong Kong https://orcid.org/0000-0001-6289-663X

\section{Wing-Kuk Au}

The University of Hong Kong

\section{Richard Kao}

University of Hong Kong

\section{Kelvin To}

The University of Hong Kong https://orcid.org/0000-0002-1921-5824

Kwok-Yung Yuen ( $\nabla$ kyyuen@hku.hk)

University of Hong Kong https://orcid.org/0000-0002-2083-1552

\section{Article}

Keywords: Influenza virus, coronavirus, endosomal acidification, drug-resistant viruses

Posted Date: February 17th, 2021

DOl: https://doi.org/10.21203/rs.3.rs-199338/v1

License: (9) This work is licensed under a Creative Commons Attribution 4.0 International License. Read Full License 


\section{Abstract}

Influenza virus, coronavirus, and drug-resistant viruses are long-term threats to public health because of lacking effective antivirals. Thus, chemicals with broad-spectrum antiviral activities and low possibility to induce drug resistance are urgently needed. Here, we identify a peptidic inhibitor P16 significantly inhibiting influenza A/B virus by binding to HA to block viral fusion. Moreover, P16 antagonizes endosomal acidification to suppress influenza virus and SARS-CoV-2 entry through the endocytic pathway. Importantly, endosomal acidification inhibitor P16 or chloroquine can broadly inhibit A(H1N1) virus, SARS-CoV and SARS-CoV-2 replication in mice and hamsters when administrated through intranasal inoculation or atomization inhalation, contrary to reported treatment failure by systemic route. Chloroquine can significantly inhibit SARS-CoV-2 replication in ex vivo human lung tissues. In conclusion, endosomal acidification inhibitors (P16 and chloroquine) can broadly inhibit influenza virus and coronavirus replication in vivo, which supports atomization inhalation of chloroquine for treating coronavirus and influenza patients in clinical trials.

\section{Introduction}

Before COVID-19, limited attention was paid on discovering anti-coronavirus drugs, even after the SARSCoV outbreak in 2003. Influenza viruses which caused pandemic and seasonal outbreaks have repeatedly overwhelmed healthcare institutions and affected socioeconomic activities. The suboptimal effectiveness of currently available anti-influenza drugs against certain strains was evidenced by the high mortality rates (> 30\%) of Influenza $A(\mathrm{H} 5 \mathrm{~N} 1)$ and $A(\mathrm{H} 7 \mathrm{~N} 9)$ virus infected patients(1, 2). Drug resistant viruses can emerge quickly in patients while on treatment with specific anti-influenza drugs such as oseltamivir and baloxavir $(3,4)$. Moreover, resistant viruses against anti-influenza neutralizing monoclonal antibody could be identified after extensive virus passaging $(5,6)$. Besides the endless influenza outbreaks, the novel SARS-CoV-2 has emerged and disseminated globally since early 2020 . Together with the circulating seasonal influenza virus, SARS-CoV-2 may cause co-infection with increased severity during the influenza season(7-9). These circulating influenza virus, coronavirus and resistant virus mutants reveal our poor capability in responding to the threats of emerging/reemerging viruses with the currently available antivirals $(1,2)$. Thus, broad-spectrum agents inhibiting both influenza virus and coronavirus with low possibility to induce drug-resistance are urgently needed for combating the emergence of novel viruses.

Antiviral peptides with broad-spectrum antiviral activities against influenza virus and/or coronavirus have showed promising prospects with little metabolic toxicity and low possibility of inducing drug-resistant viruses(10-16). Due to the lack of proofreading activity of RNA polymerases in RNA viruses, SARS-CoV-2 mutants were not infrequently found in patients during the galloping pandemic (17). Similarly, drugresistant viral mutants emerged during treatment by specific antivirals, especially the small molecular compounds including neuraminidase inhibitors, M2 and polymerase inhibitors (3, 4). Defensins, naturally existing in almost all multicellular plants and animals, have been shown to have broad antiviral activities against influenza virus, coronavirus and other viruses $(18,19)$. Moreover, defensin-induced resistant 
viruses have not been reported which is consistent with our finding that defensin-derived peptide P9R did not induce drug-resistant virus even after extensive virus passaging in the presence of $\mathrm{P} 9 \mathrm{R}(16)$. Chloroquine with broad-spectrum antiviral activities targeting host factors was effective inhibiting $\mathrm{pH}$ dependent viruses in vitro and in vivo (20-22), but not effective in vivo in some other studies with unclear reason (23-25). The broad-spectrum antiviral activity and low chance of inducing drug-resistant viruses make the defensin-derived peptide and similar host-targeting antivirals being promising candidates for drug development.

In this study, we first identified a peptidic P16, modified from frog defensin with more positive charges, which can inhibit influenza A/B virus and SARS-CoV-2. In vitro mechanistic studies demonstrated that P16 could block the low-pH induced HA conformational changes of $A(H 1 N 1), A(H 7 N 7)$ and FluB viruses. In addition, P16 could inhibit endosomal acidification and block spike-ACE2-mediated viral entry of SARSCoV-2 through the endocytic pathway. Importantly, we showed that endosomal acidification inhibitors (peptidic P16 and chemical chloroquine) could significantly inhibit $\mathrm{A}(\mathrm{H} 1 \mathrm{~N} 1)$ virus, SARS-CoV and SARSCoV-2 replication in mice and hamsters when administrated through intranasal routes (intranasal inoculation or atomization inhalation), in contrary to previous reports of treatment failure by oral chloroquine in clinical trials. We illustrated that chloroquine could effectively inhibit viral replication when given at the same route as virus challenge. Moreover, chloroquine significantly inhibited SARS-CoV-2 replication in ex vivo human lung tissues. Overall, we developed a strategy to make antiviral peptide having dual antiviral functions by direct binding leading to inhibition (i.e. blocking influenza HA conformational change) and inhibiting endosomal acidification to suppress pH-dependent viruses (i.e. blocking influenza virus and SARS-CoV-2 fusion in endolysosomes). We further demonstrated that endosomal acidification inhibitors (P16 and chloroquine) could effectively inhibit influenza virus and coronavirus replication in vivo when administrated through intranasal inoculation or atomization inhalation. The antiviral activity of atomization inhalation of chloroquine provided the evidence that chloroquine might be re-purposed for treating coronavirus and influenza virus diseases when administrated through atomization inhalation to patients, in which atomization inhalation may achieve more effective drug delivery when compared with the conventional inhalation in animal models.

\section{Results}

\section{Basic peptide $\mathrm{P} 16$ inhibited influenza $\mathrm{A}$ and $\mathrm{B}$ virus}

Our previous studies of mouse beta defensin (30 amino acid peptide) indicated that putative virusbinding peptide without antiviral activity through virus binding could be modified to have more positive charges to enhance the antiviral activity by inhibiting endosomal acidification(16). Here, from another perspective, we aimed to show that a virus-binding antiviral peptide could be modified with more positive charges to acquire dual-functional activities against virus due to the inhibition by direct binding and the enhanced inhibition on endosomal acidification. We identified short peptide $\mathrm{U} 4$ and $\mathrm{U}$, derived from a frog defensin Urumin which could bind to HA stem of group 1 influenza A virus(13), showing more potent antiviral activity than that of Urumin against $A(H 1 N 1)$ virus (Fig. 1A-1B). Based on U4 and U5, we 
identified a short 16 amino acid peptide (P16) with positive charge (+6.1), which could significantly inhibit $\mathrm{A}(\mathrm{H} 1 \mathrm{~N} 1)$ virus $\left(\mathrm{IC}_{50}=3.9 \mu \mathrm{g} \mathrm{ml}^{-1}\right.$, Fig. $\left.1 \mathrm{C}\right)$, which is lower than the $\mathrm{IC}_{50}$ of $\mathrm{U} 4\left(6.6 \mu \mathrm{g} \mathrm{ml}^{-1}\right)$ and U5 $\left(12.9 \mu \mathrm{g} \mathrm{ml}^{-1}\right)$. The potent anti-H1N1 activity of P16 was further confirmed by the inhibition on viral multicycle growth (Fig. 1D), which showed that P16 could inhibit viral replication by 41 -fold. More interestingly, $\mathrm{P} 16$ could also inhibit $\mathrm{A}(\mathrm{H} 3 \mathrm{~N} 2)\left(\mathrm{IC}_{50}=1.6 \mu \mathrm{g} \mathrm{ml}^{-1}\right)$ and FluB $\left(\mathrm{IC}_{50}=7.1 \mu \mathrm{g} \mathrm{ml}^{-1}\right)$ viruses (Fig. 1E). The cytotoxicity analysis indicated that no significant cytotoxicity of P16 on MDCK cells treated by 1 $\mathrm{mg} \mathrm{ml}^{-1}$ of $\mathrm{P} 16\left(\mathrm{TC}_{50}>1 \mathrm{mg} \mathrm{ml}^{-1}\right.$, Fig. $\left.1 \mathrm{~F}\right)$ and no significant hemolysis was observed when Turkey red blood cells (RBC) were treated by P16 (Supplementary Fig. 1). These results showed that the short basic peptide P16 could potently inhibit influenza A (group 1 and group 2) and B viruses without obvious cytotoxic effect on host cells.

\section{P16 inhibited HA fusion and endosomal acidification}

To investigate the antiviral mechanism of P16 against influenza virus, cells were treated with P16 before $A(H 1 N 1)$ virus infection, but no antiviral activity was detected (Supplementary Fig. 2). When virus was pretreated by P16 before viral infection, P16 could significantly inhibit viral replication (Fig. 2A). When infected cells were treated by P16 after viral infection, P16 did not inhibit viral replication in cells (Supplementary Fig. 3A) and viral release in supernatants (Supplementary Fig. 3B). These results indicated that the antiviral activity of P16 might rely mainly on targeting virus before viral entry. To further confirm this result, we treated $A(\mathrm{H} 1 \mathrm{~N} 1)$ virus $\left(1 \times 10^{6} \mathrm{PFU} \mathrm{ml}^{-1}\right)$ with $\mathrm{P} 16\left(500 \mu \mathrm{g} \mathrm{ml}^{-1}\right)$ and then diluted the P16-treated virus by 10, 000 folds for plaque assay. After dilution, P16 at the concentration of $0.05 \mathrm{\mu g} \mathrm{ml}^{-}$

${ }^{1}$ which is less than the $\mathrm{IC}_{50}$ of $3.9 \mathrm{\mu g} \mathrm{ml}^{-1}$, could still significantly reduce the plaque number (Fig. $2 \mathrm{~B}$ ), which further confirmed that the antiviral activity of P16 mainly relied on targeting virus and that the binding of P16 to virus was irreversible. Next, intact $\mathrm{A}(\mathrm{H} 1 \mathrm{~N} 1)$ virus treated by $\mathrm{P} 16$, similar to the untreated virus, could be detected by transmission electron microscopy (TEM). However, intact viral particle was not detected when virus was treated by Triton X-100 (Supplementary Fig. 4). These results indicated that the antiviral activity of P16 mainly relied on direct targeting of virus which interfered with viral infection at early stage without disrupting the viral particles.

Next, we used $\mathrm{A}(\mathrm{H} 5 \mathrm{~N} 1)$ pseudovirus which only expressed $\mathrm{HA}$ and NA proteins to test whether $\mathrm{P} 16$ could affect the entry of pseudovirus. As shown in Fig. 2C, P16 could significantly inhibit the entry of $A(H 5 N 1)$ pseudovirus, which indicated that P16 most likely interfered with the early step of viral infection by targeting HA. Next, P16 did not reduce the viral attachment (Fig. 2D), which also suggested that P16 did not disrupt viral particles because the viral RNA copies of attached virus were significantly reduced on cell surface (Fig. 2D) when virus was treated and disrupted by Triton X-100. We further confirmed that P16 did not have hemagglutination inhibition (HAl) activity against $A(\mathrm{H} 1 \mathrm{~N} 1)$ and FluB viruses when compared with neutralization antibody (Supplementary Fig. 5). Furthermore, unlike P9R which bound to viral surface HA and captures viral particles(16), P16 could not capture viral particles as shown in capture EIA assay (Fig. 2E and Supplementary Fig. 6), which implicated that P16 was less likely to bind to the head region of HA. Considering the broad-spectrum antiviral activities of P16 against group 1 and 2 influenza A virus 
and FluB virus, we hypothesized that P16 might bind to HA stem region so as to interfere HA conformational change. Consistently, we identified that P16 could significantly inhibit RBC hemolysis induced by group $1 \mathrm{~A}(\mathrm{H} 1 \mathrm{~N} 1)$ virus at $\mathrm{pH} 5.0$ condition (Fig. 2F). Furthermore, it was confirmed that P16 could block group $2 \mathrm{~A}(\mathrm{H} 7 \mathrm{~N} 7)-\mathrm{HA}$ and FluB virus mediated cell fusion triggered by the low $\mathrm{pH}$ in 293T cells (Fig. 2G) and MDCK cells (Supplementary Fig. 7). The low pH-treated cells without P16 showed $>2$-fold larger size than the normal cells treated by $\mathrm{pH}$ 7.4. These results indicated that $\mathrm{P} 16$ could broadly bind to stem region to block the low $\mathrm{pH}$-induced HA conformational change(26). Finally, it was demonstrated that basic $\mathrm{P} 16$ could inhibit endosomal acidification similar to the effect of bafilomycin $\mathrm{A1}$ (16) in live cells (Fig. 2H). These results indicated that P16 could have dual functions which not only blocked HA fusion by binding but also inhibited endosomal acidification to interfere viral entry through the endocytic pathway.

\section{P16 inhibited SARS-CoV-2 by interfering endosomal pH}

The broad-spectrum antiviral activity of P16 was not restricted to influenza A and B viruses. P16 could significantly inhibit SARS-CoV-2 infection with $\mathrm{IC}_{50}\left(2.8 \mathrm{\mu g} \mathrm{ml}^{-1}\right)$ as measured by plaque reduction assay (Fig. 3A). The antiviral activity of P16 mainly relied on targeting virus before viral entry (Fig. 3B) but not targeting cells when cells were treated before and after viral infection (Fig. 3C). P16 did not significantly inhibit viral release (Supplementary Fig. 8) and viral attachment (Supplementary Fig. 9) but inhibited spike-ACE2 mediated cell fusion in 293T cell (Fig. 3D). These indicated that P16 could block SARS-CoV-2 fusion with the target cells. Next, we demonstrated that P16 and U5 could bind to S protein of SARS-CoV2 (Fig. 3E) and U5 could reduce P16 binding to S protein, but not P9R binding to S protein (Fig. 5E), which indicated the competitive binding between U5 and P16 on S protein. However, U5 showed significantly weaker antiviral activity against SARS-CoV-2 infection than that of P16 (Fig. 3F) and did not inhibit spikeACE2 mediated fusion (Fig. 3D). These results suggested that the binding of U5 and P16 to S protein itself could not significantly block spike-ACE2 mediated fusion to inhibit SARS-CoV-2 infection. The enhanced fusion inhibition of P16 on SARS-CoV-2 could be attributed to the inhibition of P16 on endosomal acidification (Fig. 2H), similar with the fusion inhibition of bafilomycin A1 (Fig. 3D). We further identified that P16 could not inhibit SARS-CoV-2 replication in Calu-3 cells (Supplementary Fig. 10), which was consistent to the activity of P16 against SARS-CoV-2 by inhibiting endosomal acidification. This is same as chloroquine which cannot inhibit SARS-CoV-2 replication in Calu-3 cells(27) because chloroquine inhibited endosomal acidification but not TMPRSS2 activity.

\section{Endosomal acidification inhibitors against viruses in vivo}

To evaluate the antiviral efficacy of P16 in vivo, we challenged mice with $\mathrm{A}(\mathrm{H} 1 \mathrm{~N} 1)$ pdm09 virus. $\mathrm{P} 16$ could significantly decrease lung viral load by 12 -fold (Fig. 4A) and improve the survival of challenged mice by 80\% (Fig. 4B). The protection conferred by P16 on infected mice was similar to that of zanamivir (Fig. 4A4B). Considering the drug resistant problems of anti-influenza drugs, we tested whether the drug-resistant mutants of $A(H 1 N 1)$ virus could emerge when $A(H 1 N 1)$ virus was cultured in the presence of $P 16$ (Fig. 
4C). P16 could efficiently inhibit the replication of passaged virus (P15 and P20), with similar efficiency against the virus without any passage (P0).

Interestingly, intranasal inoculation of P16 could significantly inhibit 14-fold SARS-CoV-2 replication in hamster lungs (Fig. 4D), which indicated that blocking endosomal acidification could inhibit SARS-CoV-2 replication in vivo even though P16 did not inhibit TMPRSS2-mediated infection of SARS-CoV-2 in Calu-3 cells (Supplementary Fig. 10). Thus, we also demonstrated that intranasal administration of endosomal acidification inhibitor chloroquine $\left(2 \mathrm{mg} \mathrm{kg}^{-1}\right)$ could inhibit 2-fold SARS-CoV-2 replication in hamster lungs (Fig. 4D). We further demonstrated that intranasal administration of chloroquine could also inhibit 3.5-fold $A(\mathrm{H} 1 \mathrm{~N} 1)$ virus replication in mice (Fig. 4E) when compared with mock, which was also less potent than that of $\mathrm{P} 16$ (12-fold) against $\mathrm{A}(\mathrm{H} 1 \mathrm{~N} 1)$ virus. To understand the highly significant antiviral effect of chloroquine against influenza virus and coronavirus in cell culture (Supplementary Fig. 11), but poor treatment effect in vivo, we identified that chloroquine could not provide 1-day prophylactic activity inhibiting SARS-CoV and A(H1N1) virus replication in BALB/c mice (Supplementary Fig. 12), even though chloroquine has a long half life time (28). This indicated that the accumulation of chloroquine in endosomes but not in serum and cytosolic environment of lungs (25) did not provide the antiviral activity against $\mathrm{pH}$-dependent viruses in vivo. Chloroquine could effectively inhibit viral replication when virus was treated with chloroquine during viral infection (Fig. 4F). However, treating cells with chloroquine before or after SARS-COV-2 infection, which did not effectively let chloroquine enter cells with virus together, showed significantly less antiviral activity than treating cells during viral infection (Fig. 4F). Thus, we speculated that chloroquine can exhibit antiviral activity in vivo if lung cells are constantly exposed to chloroquine with effective concentration against $\mathrm{pH}$-dependent viruses. We demonstrated that one dose of chloroquine could inhibit (3-5)-fold SARS-CoV and A(H1N1) virus replication in BALB/c mice when chloroquine was intranasally administrated into mouse lungs at the time before viral inoculation (Supplementary Fig. 13).

Most importantly, we demonstrated that atomization inhalation of chloroquine could inhibit SARS-CoV and $\mathrm{A}(\mathrm{H} 1 \mathrm{~N} 1)$ virus replication in mice (Fig. 4G-4H), which provided the evidence that atomization inhalation of chloroquine is an achievable method in clinical treatment for coronavirus patients and influenza patients. These in vivo data provided the information that the endosomal acidification inhibitor chloroquine, which could not inhibit coronavirus or influenza virus replication in vivo when administrated by oral inoculation (Supplementary Fig. 14 ) or intraperitoneal injection $(24,25,29,30$ ), might effectively inhibit coronavirus and influenza virus replication in humans if chloroquine could be administrated to lungs by intranasal routes to provide effective chance of keeping lung cells in the bath of chloroquine environment. Thinking about the TMPRSS2-mediated entry pathway of SARS-CoV-2 in humans, we further demonstrated that chloroquine could significantly inhibit SARS-CoV-2 replication in ex vivo human lung tissues which were kept in the bath of chloroquine (Fig. 4I). Overall, we demonstrated that endosomal acidification inhibitors (P16 and chloroquine) could significantly inhibit SARS-CoV-2, SARS$\mathrm{CoV}$ and influenza $\mathrm{A}(\mathrm{H} 1 \mathrm{~N} 1)$ virus replication in vivo through intranasal administration when lung cells could be bathed in chloroquine with effective concentration. 


\section{Discussion}

In this study, we identified that endosomal acidification inhibitors (peptidic P16 and chemical chloroquine) could suppress influenza virus and coronavirus infection in vitro and in vivo. Dual-functional P16 could inhibit influenza virus by blocking influenza HA conformation change and inhibiting endosomal acidification to block pH-dependent influenza and coronavirus fusion. Importantly, we demonstrated that both endosomal acidification inhibitors (P16 and chloroquine) could effectively inhibit A(H1N1) and SARS-CoV-2 replication in mice and hamsters. Chloroquine could significantly inhibit SARSCoV-2 replication in ex vivo human lung tissues, which indicated that chloroquine might significantly inhibit SARS-CoV-2 replication in human lungs when chloroquine could be delivered into lungs with effective concentration.

Broad-spectrum antivirals, like peptides binding to HA stem region, have been found to inhibit group 1 influenza A viruses $(13,26)$. However, the stem region is not very conserved in influenza virus(31), which may pose a challenge to find an universal antiviral against influenza virus by targeting the HA stem region. Here, we reported the peptidic P16 inhibiting HA-mediated cell fusion of group $1 A(H 1 N 1)$, group 2 $A(H 7 N 7)$ and FluB viruses, which provided the evidence that an antiviral peptide could be a fusion inhibitor with broad-spectrum activities against both influenza $A$ and $B$ viruses. Moreover, basic P16 could bind to viruses and inhibit influenza virus and SARS-CoV-2 by preventing endosomal acidification. Broadspectrum antiviral, like chloroquine elevating the endosomal $\mathrm{pH}$ of host cells without binding to virus, had been identified to inhibit viruses in vitro and in vivo $(20,21)$. However, a number of studies demonstrated the lack of antiviral activity of chloroquine in vivo $(24,25,32)$. Here, we identified both endosomal acidification inhibitors (P16 and chloroquine) could inhibit A(H1N1) virus in mice and SARS-CoV-2 replication in hamsters when administrated through intranasal routes. We demonstrated that treating mice with chloroquine before viral inoculation could effectively inhibit influenza and coronavirus replication in vivo. However, one-day prophylactic treatment with chloroquine could not show antiviral activity against influenza and coronavirus in mice. We further illustrated that the effective way to use chloroquine against $\mathrm{pH}$-dependent virus is to provide a high enough concentration of chloroquine when virus is entering cells (Fig. $4 \mathrm{~J}$ ). Thus, it is important to provide the effective chance of keeping lung cells in chloroquine environment, which could effectively inhibit viral RNA release by preventing virusendosome acidification.

Because of the high mutation rates resulting antigenic drift, influenza vaccines could only provide $10 \sim$ $60 \%$ protection during the past decades. Since the discovery of neuraminidase inhibitors in 1990(33), M2 inhibitor(34), and polymerase inhibitor(4) have been found. However, viruses resistant to these inhibitors quickly emerged even during the clinical trials $(3,4,35)$. In addition, with the circulation of pandemic SARS-CoV-2, different mutants have been reported. Thus, antivirals with new acting mechanism and broad-spectrum activities against viruses with less possibility to induce drug resistance are needed for treating influenza virus and coronavirus. P16 derived from frog defensin could broadly inhibit influenza A and $B$ viruses and SARS-CoV-2 with low possibility to cause influenza drug-resistant virus. No drugresistant virus was found after 20 viral passages in the presence of P16. Interestingly and importantly, 
chloroquine, despite not showing effective antiviral activity in vivo $(23,24,29,30)$ when administrated through systemic routes in many studies, could target host endosomes to block pH-dependent viral infection and significantly inhibit influenza virus and coronavirus replication in mice and hamsters when administrated by intranasal routes. The host-targeting antiviral activity of chloroquine indicates that chloroquine is less likely to induce drug-resistant problem. Currently, the rapid RT-PCR test can identify patients in the early period of infection which allows atomization of these endosomal acidification inhibitors to treat SARS-CoV-2 patients. For late presenters when the peak of viral load has passed, antiviral drugs given by any routes are unlikely to improve the outcome. Immunomodulatory agents such as steroid may play a more important therapeutic role. In addition, chloroquine could suppress the expression of inflammation cytokines in human lungs (36). Thus, the topical administration of chloroquine by atomization inhalation in the early period of infection may not only enhance the antiviral efficacy in lungs but also reduce the potential cardiac side effects when compared with systemic administration by oral or intravenous injection. These data give us evidences to support the use of endosomal acidification inhibitor chloroquine as a broad-spectrum antiviral candidate to treat coronavirus, influenza or co-infection of coronavirus and influenza virus in clinical trials through atomization inhalation.

\section{Material And Methods}

\section{Cell and virus culture}

Madin Darby canine kidney (MDCK, CCL-34), Vero-E6 (CRL-1586), 293T (CRL-3216), and Calu-3 (HTB-55) cells obtained from ATCC (Manassas, VA, USA) were cultured in Dulbecco minimal essential medium (DMEM) or MEM supplemented with $10 \%$ fetal bovine serum (FBS), $100 \mathrm{IU} \mathrm{ml}^{-1}$ penicillin and $100 \mu \mathrm{g}$ $\mathrm{ml}^{-1}$ streptomycin. The virus strains used in this study included A/Hong Kong/415742M/2009(H1N1), A/Hong Kong/4801/2014(H3N2), A/Netherlands/219/2003(H7N7), A/Anhui/1/2013(H7N9), influenza B/TW/70555/05(FluB), SARS-CoV, and SARS-CoV-2(16, 37).

\section{Plaque reduction assay}

Peptides were synthesized by ChinaPeptide. Antiviral activity of peptides was measured using a plaque reduction assay. Briefly, peptides or bovine serum albumin (BSA, $0.2-50.0 \mathrm{\mu g} \mathrm{ml}^{-1}$ ) were premixed with 50 PFU of virus in PBS at room temperature. After 45-60 min of incubation at room temperature, peptidevirus mixture was transferred to MDCK or Vero-E6 cells, correspondingly. At $1 \mathrm{~h}$ post infection, infectious media were removed and $1 \%$ low melting agar was added to cells. Cells were fixed using $4 \%$ formalin at 2-3 day post infection. Crystal violet $(0.1 \%)$ was added for staining, and the number of plaques was counted.

\section{Viral RNA extraction and RT-qPCR}


Viral RNA was extracted by Viral RNA Mini Kit (QIAGEN, Cat ${ }^{\#}$ 52906, USA) according to the manufacturer's instructions. Extracted RNA was reverse transcribed to cDNA using PrimeScript II $1^{\text {st }}$ Strand cDNA synthesis Kit (Takara, Cat ${ }^{\#}$ 6210A) with GeneAmp® PCR system 9700 (Applied Biosystems, USA). The cDNA was then amplified using specific primers (Supplementary Table 1) for detecting A(H1N1) virus using LightCycle ${ }^{\circledR} 480$ SYBR Green I Master (Roach, USA). For quantitation, 10-fold serial dilutions of standard plasmid equivalent to $10^{1}$ to $10^{6}$ copies per reaction were prepared to generate the calibration curve. Real-time qPCR experiments were performed using LightCycler ${ }^{\circledR} 96$ system (Roche, USA).

\section{Antiviral multicycle growth assay}

Influenza viruses were pretreated by peptide and then infected MDCK cells $(0.005 \mathrm{MOI})$. After $1 \mathrm{~h}$ infection, infectious media were removed and fresh media with supplemental peptides were added to infected cells for virus culture. At $18 \mathrm{~h}$ post infection, the supernatants of infected cells were collected for RT-qPCR assay to determine the viral titers in cell supernatants.

\section{Cytotoxicity assay}

Cytotoxicity of peptides was determined by the detection of $50 \%$ cytotoxic concentration $\left(\mathrm{CC}_{50}\right)$ using a tetrazolium-based colorimetric MTT assay. Briefly, MDCK cells were seeded in 96-well cell culture plate at an initial density of $2 \times 10^{4}$ cells per well in DMEM supplemented with $10 \%$ FBS and incubated for overnight. Cell culture media were removed and then DMEM supplemented with various concentrations of peptides and $1 \%$ FBS were added to each well. After $24 \mathrm{~h}$ incubation at $37^{\circ} \mathrm{C}$, MTT solution $\left(5 \mathrm{mg} \mathrm{ml}^{-1}\right.$, $10 \mu \mathrm{l}$ per well) was added to each well for incubation at $37^{\circ} \mathrm{C}$ for $4 \mathrm{~h}$. Then, $100 \mu \mathrm{l}$ of $10 \%$ SDS in $0.01 \mathrm{M}$ $\mathrm{HCl}$ was added to each well. After further incubation at room temperature with shaking overnight, the plates were read at $\mathrm{OD}_{570}$ using VictorTM X3 Multilabel Reader (PerkinElmer, USA). Cell culture wells without peptides were used as the experiment control and medium only served as a blank control.

\section{Hemolysis and hemolysis inhibition assay}

Serially diluted peptide P16 in PBS were incubated with turkey red blood cells for $1 \mathrm{~h}$ at $37^{\circ} \mathrm{C}$. PBS was used as a $0 \%$ lysis control and $0.1 \%$ Triton X-100 as $100 \%$ lysis control. Plates were centrifuged at $350 \mathrm{~g}$ for 3 min to pellet non-lysed red blood cells. Supernatants used to measure hemoglobin release were detected by absorbance at $450 \mathrm{~nm}$. For hemolysis inhibition assay, P16 $\left(200 \mu \mathrm{g} \mathrm{ml}^{-1}\right), \mathrm{P} 9 \mathrm{R}\left(200 \mu \mathrm{g} \mathrm{ml}^{-1}\right)$ or arbidol $\left(100 \mathrm{~g} \mathrm{ml}^{-1}\right)$ were mixed with or without same volume of H1N1 virus (HA titer $\left.>128\right)$ for $1 \mathrm{~h}$, and then $60 \mu \mathrm{l}$ of $2 \%$ turkey red blood cells was added for $15 \mathrm{~min}$. PBS and Triton X-100 (0.1\%) were included as the negative and positive control of hemolysis. The precipitated erythrocytes were incubated with sodium citrate solution ( $\mathrm{pH}$ of 4.9) for $25 \mathrm{~min}$. The hemoglobin release in supernatants was detected at $450 \mathrm{~nm}$.

\section{Transmission electron microscopy assay}


To determine the effect of $\mathrm{P} 16$ on viral particles, $\mathrm{A}(\mathrm{H} 1 \mathrm{~N} 1)$ virus was pretreated by $200 \mu \mathrm{g} \mathrm{ml}^{-1}$ of $\mathrm{P} 16, \mathrm{PBS}$ or Triton X-100 $(0.15 \%)$ for $1 \mathrm{~h}$. The virus was fixed by formalin for overnight and then applied to continuous carbon grids. The grids were transferred into $4 \%$ uranyl acetate and incubated for $1 \mathrm{~min}$. After removing the solution, the grids were air-dried at room temperature. For each sample, two-three biological samples were done for taking TEM images by FEI Tecnal G2-20 TEM.

\section{H5N1 pseudovirus assay}

H5N1 pseudotype virus(38) bearing H5N1 HA and NA was pretreated with PBS or P16 in PBS and then incubated at RT for $1 \mathrm{~h}$. MDCK cells were infected with the treated pseudotype virus for $1 \mathrm{~h}$. MDCK cells without pseudotype virus infection were served as the baseline control of luciferase protein. After $18 \mathrm{~h}$ cell culture, cell lysates were collected and the luciferase protein was measured by Luciferase assay system (Promega) in a Victor X3 Multilabel reader (PerkinElmer). The luminescence reading was normalized to $1 \mathrm{mg}$ protein.

\section{Virus induced cell fusion assay}

MDCK cells were transfected with pGFP. Eight hour later, cells were infected with $1 \mathrm{MOI}$ of FluB virus. At $18 \mathrm{~h}$ post infection, cells were treated by PBS or $\mathrm{P} 16$ for $1 \mathrm{~h}$ and then cells were treated by $\mathrm{pH} 5.0$ or $\mathrm{pH} 7.4$ for $10 \mathrm{~min}$. After removing the $\mathrm{pH}$ buffer, cells were cultured at $37^{\circ} \mathrm{C}$ for $4 \mathrm{~h}$ with full media. Fusion pictures were taken at $4 \mathrm{~h}$ after $\mathrm{pH}$ treatment.

\section{HA mediated cell fusion assay}

The 293T cells were co-transfected with pGFP and pH7N7-HA. At 24h post transfection, cells were treated by PBS or $\mathrm{P} 16$ for $1 \mathrm{~h}$ and then treated by $\mathrm{pH} 5.0$ or $\mathrm{pH} 7.4$ for $10 \mathrm{~min}$. After removing the $\mathrm{pH}$ buffer, cells were cultured at $37^{\circ} \mathrm{C}$ for $4 \mathrm{~h}$ with full media. Fusion pictures were taken at $4 \mathrm{~h}$ after $\mathrm{pH}$ treatment.

\section{Spike-ACE2 mediated cell fusion assay}

The pSpike of SARS-CoV-2, pACE2-human, or pGFP were transfected to 293T cells for protein expression. After 24 hours, to trigger the spike-ACE2 mediated cell fusion, 293T-Spike-GFP cell were co-cultured with 293T-ACE2 with or without the supplement of peptide or drug. The 293T-GFP cells were co-cultured with 293T-ACE2 cells as the no-fusion negative control. After $8 \mathrm{~h}$ of co-culture, five fields were randomly selected in each well to take the cell fusion pictures by fluorescence microscopes.

\section{Peptide binding assay}

Peptides (1.0-3.0 $\mu \mathrm{g}$ per well) dissolved in $\mathrm{H}_{2} \mathrm{O}$ were coated onto ELISA plates and incubated at $4{ }^{\circ} \mathrm{C}$ overnight. Then, $2 \%$ BSA was used to block plates at $4^{\circ} \mathrm{C}$ overnight. For virus or spike protein binding to peptides, viruses or spike protein were diluted in PBS and then were added to ELISA plate for binding to the coated peptides at room temperature for $1 \mathrm{~h}$. After washing the unbound viruses or spike protein, the bound viruses were lysed by RLT buffer of RNeasy Mini Kit (Qiagen, Cat\# 74106) for viral RNA extraction. 
Viral RNA copies of binding viruses were measured by RT-qPCR. The bound spike protein detected by antiHis-HRP (Invitrogen, Cat\# R93125, 1: 2,000) by reading $\mathrm{OD}_{450}$.

\section{Endosomal acidification assay}

Endosomal acidification was detected with a pH-sensitive dye (pHrodo Red dextran, Invitrogen, Cat $\left.{ }^{\#} \mathrm{P} 10361\right)$ according to the manufacturer's instructions as previously described but with slight modification(3). First, MDCK cells were treated with BSA $\left(25.0 \mu \mathrm{g} \mathrm{ml}^{-1}\right), \mathrm{P} 16\left(25.0 \mu \mathrm{g} \mathrm{ml}^{-1}\right)$ and bafilomycin A1 (50 nM) at $4{ }^{\circ} \mathrm{C}$ for $15 \mathrm{~min}$. Second, MDCK cells were added with $100 \mu \mathrm{g} \mathrm{ml}^{-1} \mathrm{of} \mathrm{pH}-$ sensitive dye and DAPI and then incubated at $4{ }^{\circ} \mathrm{C}$ for $15 \mathrm{~min}$. Before taking images, cells were further incubated at $37^{\circ} \mathrm{C}$ for $15 \mathrm{~min}$ and then cells were washed twice with PBS. Finally, PBS was added to cells and images were taken immediately with confocal microscope (Carl Zeiss LSM 700, Germany).

\section{Rearing of virus resistant mutant}

$\mathrm{A}(\mathrm{H} 1 \mathrm{~N} 1)$ virus was pretreated by $\mathrm{P} 16$ and then infected MDCK cells. After $1 \mathrm{~h}$ infection, MEM media with the supplement $\mathrm{P} 16$ were added to cells for virus culture. At $24 \mathrm{~h}$ post infection, viruses were collected for next passages. After 20 passages, passaged viruses (P20 and P15) and virus without passage (P0) were pretreated by P16 or PBS with the indicated concentration of P16 for MDCK infection. At $18 \mathrm{~h}$ post infection, viral loads in cell supernatants were measured by RT-qPCR to identify the sensitivity of passaged viruses to P16.

\section{Hemagglutination inhibition assay}

HA titers of H1N1 and FluB viruses were tested by TRBC. Viruses (8HA titer) were premixed with peptides or PBS for $1 \mathrm{~h}$ and then equal volume of TRBC was added to virus for incubation at room temperature for $30 \mathrm{~min}$. The precipitates of TRBC were record for calculating the HAl activity. TRBC with untreated virus and neutralization antibody from serum were served as negative and positive control of hemagglutination inhibition.

\section{Human Ex Vivo Lung Tissues}

Human lung tissues for ex vivo studies were obtained from patients undergoing surgical operations at Queen Mary Hospital, Hong Kong, as we previously described (39). All donors gave written consent as approved by the Institutional Review Board of the University of Hong Kong/Hospital Authority Hong Kong West Cluster (UW13-364). The freshly obtained lung tissues were processed into small pieces and then were infected with SARS-CoV-2 $\left(2 \times 10^{4}\right.$ PFU) in $500 \mu$ advanced Dulbecco's Modified Eagle's Medium (DMEM)/F12 medium (Gibco, Thermo Fisher Scientific) supplemented with $100 \mathrm{U} / \mathrm{mL}$ penicillin, 100 $\mu \mathrm{g} / \mathrm{mL}$ streptomycin and chloroquine $(5 \mu \mathrm{g} / \mathrm{ml})$. After 18 hours, the inoculum was removed and the specimens were washed one time with PBS. The infected human lung tissues were then cultured in $0.5 \mathrm{ml}$ of advanced DMEM/F12 medium with chloroquine $(5 \mu \mathrm{g} / \mathrm{ml})$. Supernatants were collected at 60 hours post inoculation for plaque assays. 
BALB/c female mice (10-12 weeks for H1N1 virus and 10-12 months for SARS-CoV) and female hamsters (4-6 weeks for SARS-CoV-2) were kept in biosafety level 2 laboratory (housing temperature between $22 \sim 25^{\circ} \mathrm{C}$ with dark/light cycle) and given access to standard pellet feed and water ad libitum. All experimental protocols followed the standard operating procedures of the approved biosafety level 2 animal facilities and were approved by the Committee on the Use of Live Animals in Teaching and Research of the University of Hong Kong(40). To evaluate the therapeutic effect, mice were intranasally inoculated with $3 \mathrm{LD}_{50}$ of $\mathrm{A}(\mathrm{H} 1 \mathrm{~N} 1)$ virus or hamsters were intranasally inoculated with $5000 \mathrm{PFU}$ of SARS-CoV-2 and then intranasally inoculated with PBS, P16, zanamivir, or chloroquine at 6-8 $\mathrm{h}$ after the viral inoculation. Two more doses were given to the challenged mice on the following day. Survival and general conditions were monitored for 14 days or until death. Viral loads in lungs were measured at day 2 post infection. To evaluate the prophylactic effect, mice were intranasally inoculated with chloroquine at 1-day or 1-min before viral inoculation with 200 PFU of A(H1N1) virus or 5000 PFU of SARS-CoV to mouse lungs. To evaluate the antiviral activity of chloroquine atomization, mice were given the atomized chloroquine and then $\mathrm{A}(\mathrm{H} 1 \mathrm{~N} 1)$ or SARS-CoV were inoculated to mouse lungs. The viral loads in lungs were measured at day 1 post infection.

\section{Declarations}

\section{Acknowledgements}

Thanks for Prof. Shin-Ru Shih of Chang Gung University of Taiwan providing us FluB strain. This study was partly supported by the donations of Richard Yu and Carol Yu, Michael Seak-Kan Tong, May Tam Mak Mei Yin, the Shaw Foundation Hong Kong, Respiratory Viral Research Foundation Limited, Hui Ming, Hui Hoy and Chow Sin Lan Charity Fund Limited, Chan Yin Chuen Memorial Charitable Foundation, Marina Man-Wai Lee, the Hong Kong Hainan Commercial Association South China Microbiology Research Fund, the Jessie \& George Ho Charitable Foundation, Perfect Shape Medical Limited, and Kai Chong Tong; and the National Program on Key Research Project of China (grant no. 2020YFA0707500 and 2020YFA0707504). The funding sources had no role in the study design, data collection, analysis, interpretation, or writing of the report.

\section{Conflict of interest}

The authors declare that they have no conflict of interest.

\section{Data availability.}

All data that support the conclusions of the study are available from the corresponding author upon request.

\section{References}


1. T. Horimoto, Y. Kawaoka, Influenza: lessons from past pandemics, warnings from current incidents. Nat Rev Microbio/ 3, 591-600 (2005).

2. T. Watanabe, S. Watanabe, E. A. Maher, G. Neumann, Y. Kawaoka, Pandemic potential of avian influenza A (H7N9) viruses. Trends Microbiol 22, 623-631 (2014).

3. H. Zhao et al., Dual-functional peptide with defective interfering genes effectively protects mice against avian and seasonal influenza. Nat Commun 9, 2358 (2018).

4. F. G. Hayden et al., Baloxavir Marboxil for Uncomplicated Influenza in Adults and Adolescents. NEngl J Med 379, 913-923 (2018).

5. N. Chai et al., Two Escape Mechanisms of Influenza A Virus to a Broadly Neutralizing Stalk-Binding Antibody. PLoS Pathog 12, e1005702 (2016).

6. N. C. Wu et al., Different genetic barriers for resistance to HA stem antibodies in influenza $\mathrm{H} 3$ and $\mathrm{H} 1$ viruses. Science 368, 1335-1340 (2020).

7. X. Zheng et al., Co-infection of SARS-CoV-2 and Influenza virus in Early Stage of the COVID-19 Epidemic in Wuhan, China. J Infect 81, e128-e129 (2020).

8. E. Cuadrado-Payán et al., SARS-CoV-2 and influenza virus co-infection. Lancet 395, e84 (2020).

9. A. J. Zhang et al., Co-infection by severe acute respiratory syndrome coronavirus 2 and influenza $\mathrm{A}(\mathrm{H} 1 \mathrm{N1})$ pdm09 virus enhances the severity of pneumonia in golden Syrian hamsters. Clin Infect Dis, (2020).

10. S. Xia et al., Inhibition of SARS-CoV-2 (previously 2019-nCoV) infection by a highly potent pancoronavirus fusion inhibitor targeting its spike protein that harbors a high capacity to mediate membrane fusion. Cell Res 30, 343-355 (2020).

11. S. Xia et al., A pan-coronavirus fusion inhibitor targeting the HR1 domain of human coronavirus spike. Sci Adv 5, eaav4580 (2019).

12. C. Wang et al., De Novo Design of a-Helical Lipopeptides Targeting Viral Fusion Proteins: A Promising Strategy for Relatively Broad-Spectrum Antiviral Drug Discovery. J Med Chem 61, 87348745 (2018).

13. D. J. Holthausen et al., An Amphibian Host Defense Peptide Is Virucidal for Human H1 Hemagglutinin-Bearing Influenza Viruses. Immunity 46, 587-595 (2017).

14. E. Leikina et al., Carbohydrate-binding molecules inhibit viral fusion and entry by crosslinking membrane glycoproteins. Nat Immunol 6, 995-1001 (2005).

15. H. Zhao et al., A novel peptide with potent and broad-spectrum antiviral activities against multiple respiratory viruses. Sci Rep 6, 22008 (2016).

16. H. Zhao et al., A broad-spectrum virus- and host-targeting peptide against respiratory viruses including influenza virus and SARS-CoV-2. Nat Commun 11, 4252 (2020).

17. T. Koyama, D. Platt, L. Parida, Variant analysis of SARS-CoV-2 genomes. Bull World Health Organ 98 , 495-504 (2020). 
18. D. C. Brice, G. Diamond, Antiviral Activities of Human Host Defense Peptides. Curr Med Chem 27, 1420-1443 (2020).

19. J. Ding, Y. Y. Chou, T. L. Chang, Defensins in viral infections. J Innate Immun 1, 413-420 (2009).

20. E. Keyaerts et al., Antiviral activity of chloroquine against human coronavirus OC43 infection in newborn mice. Antimicrob Agents Chemother 53, 3416-3421 (2009).

21. Y. Yan et al., Anti-malaria drug chloroquine is highly effective in treating avian influenza A H5N1 virus infection in an animal model. Cell Res 23, 300-302 (2013).

22. M. Huang, et al., Preliminary evidence from a multicenter prospective observational study of the safety and efficacy of chloroquine for the treatment of COVID-19. Nat Sci Rev. (2020).

23. D. Falzarano et al., Lack of protection against ebola virus from chloroquine in mice and hamsters. Emerg Infect Dis 21, 1065-1067 (2015).

24. P. Maisonnasse et al., Hydroxychloroquine use against SARS-CoV-2 infection in non-human primates. Nature, (2020).

25. S. J. F. Kaptein et al., Favipiravir at high doses has potent antiviral activity in SARS-CoV-2-infected hamsters, whereas hydroxychloroquine lacks activity. Proc Natl Acad Sci U S A 117, 26955-26965 (2020).

26. R. U. Kadam et al., Potent peptidic fusion inhibitors of influenza virus. Science 358, 496-502 (2017).

27. M. Hoffmann et al., Chloroquine does not inhibit infection of human lung cells with SARS-CoV-2. Nature, (2020).

28. H. A. Karunajeewa et al., Pharmacokinetics of chloroquine and monodesethylchloroquine in pregnancy. Antimicrob Agents Chemother 54, 1186-1192 (2010).

29. D. J. Vigerust, J. A. McCullers, Chloroquine is effective against influenza A virus in vitro but not in vivo. Influenza Other Respir Viruses 1, 189-192 (2007).

30. H. Zhao et al., Cross-linking peptide and reporpused drugs inhibit both entry pathways of SARS-CoV2. Nat Commun. Accepted in Jan, 2021.

31. J. Sui et al., Structural and functional bases for broad-spectrum neutralization of avian and human influenza A viruses. Nat Struct Mol Biol 16, 265-273 (2009).

32. N. I. Paton et al., Chloroquine for influenza prevention: a randomised, double-blind, placebo controlled trial. Lancet Infect Dis 11, 677-683 (2011).

33. S. Kubo, T. Tomozawa, M. Kakuta, A. Tokumitsu, M. Yamashita, Laninamivir prodrug CS-8958, a longacting neuraminidase inhibitor, shows superior anti-influenza virus activity after a single administration. Antimicrob Agents Chemother 54, 1256-1264 (2010).

34. A. D. Balgi et al., Inhibitors of the influenza A virus M2 proton channel discovered using a highthroughput yeast growth restoration assay. PLoS One 8, e55271 (2013).

35. R. W. Finberg et al., Phase 2b Study of Pimodivir (JNJ-63623872) as Monotherapy or in Combination With Oseltamivir for Treatment of Acute Uncomplicated Seasonal Influenza A: TOPAZ Trial. J Infect Dis 219, 1026-1034 (2019). 
36. S. Grassin-Delyle, et al., Chloroquine inhibits the release of inflammatory cytokines by human lung explants. Clin Infect Dis. 71:2265 (2020)

37. H. Zhao et al., Novel residues in the PA protein of avian influenza H7N7 virus affect virulence in mammalian hosts. Virology 498, 1-8 (2016).

38. K. K. Lai et al., Identification of Novel Fusion Inhibitors of Influenza A Virus by Chemical Genetics. Journal of virology 90, 2690-2701 (2015).

39. Chu, H. et al. Comparative Replication and Immune Activation Profiles of SARS-CoV-2 and SARS-CoV in Human Lungs: An Ex Vivo Study with Implications for the Pathogenesis of COVID-19. Clin Infect Dis, (2020).

40. B. J. Zheng et al., Delayed antiviral plus immunomodulator treatment still reduces mortality in mice infected by high inoculum of influenza A/H5N1 virus. Proc Natl Acad Sci U S A 105, 8091-8096 (2008).

\section{Unsectioned Figure Details}

A

Fig. 1

Identification of short basic peptide against influenza A and B viruses. (A) Peptide sequences and their positive charges calculated by PepCalc of InnovaGen related to pH 7.0. (B) The antiviral activity of peptides against $A(H 1 N 1)$ virus $(n=3)$. Virus was pretreated by peptides with the indicated concentrations for infection in MDCK cells. Viral RNA copies in cell lysate were measured by RT-qPCR at 5 $h$ post infection. Relative replication is defined as the percentage of RNA copies of treated samples relative to those of untreated virus. (C) Antiviral activity of peptides against $A(H 1 N 1)$ virus were measured by plaque reduction assay $(n=3)$. (D) Antiviral activity of $P 16$ against $A(H 1 N 1)$ virus were measured by RT-qPCR to test the viral RNA copies in supernatants of $18 \mathrm{~h}$ post infection $(n=3)$. ** indicates $P<0.01$. $P$ value was calculated by the two-tailed Student's t test when compared with PBS. (E) Antiviral viral activities of $\mathrm{P} 16$ against $A(\mathrm{H} 3 \mathrm{~N} 2)$ and influenza $B(F / u B)$ viruses were measured by plaque reduction assay $(n=4)$. (F) Cytotoxicity of P16 in MDCK cells $(n=3)$. Data are presented as mean \pm SD of independent biological samples.

A

Fig. 2

P16 blocked HA conformation change and endosomal acidification. (A) P16 could significantly inhibit viral replication when virus was pretreated by P16 before viral infection $(n=5)$. Viral RNA copies in cell lysates were measured by RT-qPCR at $5 \mathrm{~h}$ post infection. (B) P16 showed irreversible antiviral activity $(\mathrm{n}=$ 3). Virus $\left(1 \times 10^{6} \mathrm{PFU} / \mathrm{ml}\right)$ was pretreated by $\mathrm{P} 16\left(500 \mu \mathrm{g} \mathrm{ml}^{-1}\right)$ and then was diluted to 1,000 folds for plaque assay. $P$ values were calculated by the two-tailed Student's $t$ test when compared with BSA. (C) P16 could effectively inhibit H5N1-pseudovirus entry $(n=5)$. H5N1 pseudovirus was pretreated by P16 $\left(50 \mathrm{\mu g} \mathrm{ml}^{-1}\right)$ for cell infection in $293 \mathrm{~T}$ cells. Luciferase expression was measured at $24 \mathrm{~h}$ post infection. 
Untreated pseudovirus (PBS) and uninfected cell (Mock) were served as controls. P values were calculated when compared with PBS. (D) P16 did not affect $A(H 1 N 1)$ viral attachment $(n=3)$. A(H1N1) virus was pretreated by P16, P9RS (peptide without antiviral activity), neutralizing antibody (Ab) and Triton X-100 for $45 \mathrm{~min}$ and then attached to MDCK cells at $4^{\circ} \mathrm{C}$ for $1 \mathrm{~h}$. After washing, attached virus was measured by RT-qPCR. P values were calculated when compared with P9RS. (E) P16 could not capture $A(H 1 N 1)$ viral particles $(n=3)$. P16, P9R (positive control), P9RS and BSA (negative control) were coated on ELISA plate, which was blocked by BSA. A(H1N1) virus was added to ELISA plate for binding. After washing the unbound virus, viral RNA copies were measured to indicate the bound virus. $P$ values were calculated by comparison with P9R. (F) P16 could block hemolysis induced by $A(H 1 N 1)$ virus at low pH5.0 $(n=8)$. P values were calculated by the two-tailed Student's t test when compared with PBS. * indicates $P<0.05$. ** indicates $P<0.01$. Data are presented as mean $\pm S D$ of independent biological samples. (G) P16 could block HA-mediated cell-cell fusion triggered by low pH-induced HA conformational change. HA of A(H7N7) virus and GFP were expressed in 293T cells. Cells pretreated by $\mathrm{P} 16\left(500 \mu \mathrm{g} \mathrm{ml}^{-1}\right)$ or untreated cells were challenged by $\mathrm{pH} 5.0$ for $10 \mathrm{~min}$ to trigger the fusion. Cells challenged by pH 7.4 were served as no-fusion control. Scale bar $=100 \mu \mathrm{m}$. Experiments were repeated twice. $(\mathrm{H}) \mathrm{P} 16$ could inhibit endosomal acidification. MDCK cells were treated by BSA $\left(25 \mu \mathrm{g} \mathrm{ml}^{-1}\right), \mathrm{P} 16$ $\left(25 \mathrm{~g} \mathrm{~m} \mathrm{~m}^{-1}\right)$ or bafilomycin A1 (50 nM) and pH sensitive dye. Red dots indicated the acidic endosomes. Blue indicated the cell nuclei. Scale bar $=20 \mu \mathrm{m}$. Experiments were repeated twice.

A

Fig. 3

P16 inhibited SARS-CoV-2 infection. (A) Antiviral activity of P16 against SARS-CoV-2 in Vero-E6 cells ( $\mathrm{n}=$ 3). SARS-CoV-2 was premixed with P16 for cell infection. Plaque No (\%) was plaque No of P16-treated virus normalized to plaque No of untreated virus. (B) SARS-CoV-2 was pretreated by P16 and then infected cells for $1 \mathrm{~h}$. Viral RNA copies in cell lysates were measured by RT-qPCR at $8 \mathrm{~h}$ post infection $(\mathrm{n}=$ 5). (C) Cells were pretreated by P16 (Pretreat cell) before viral infection and P16 was added to cells at $1 \mathrm{~h}$ post infection (Post-treat). At $8 \mathrm{~h}$ post infection, viral RNA copies in cell lysates were measured by RTqPCR $(n=3) . * \star$ indicates $P<0.01$ when compared with PBS. (D) P16 could inhibit spike-ACE2 mediated cell fusion. The 293T cells were transfected with pGFP + spike or pACE2, separately. At $24 \mathrm{~h}$ later, two transfected cells were co-cultured with the addition of drug P16 $\left(250 \mu \mathrm{g} \mathrm{ml}^{-1}\right), \mathrm{U} 5\left(250 \mu \mathrm{g} \mathrm{ml}^{-1}\right)$ and bafilomycin A1(BA1, $50 \mathrm{nM}$ ). The fusion pictures were taken at $4 \mathrm{~h}$ post co-culture. Cells with GFP-spike only were served as the no-fusion control. Scale bar $=100 \mu \mathrm{m}$. Experiments were repeated twice. (E) P16 could bind to S protein and U5 could block P16 binding to S protein $(n=4)$. S protein of SARS-CoV-2 and $S$ treated by U5 ( $\mathrm{S}+\mathrm{U} 5$ ) were added to ELISA plate for binding to peptides coated on ELISA plate. * indicates $P<0.05$ when compared with untreated $S$. (F) U5 showed weaker antiviral activity than that of P16 against SARS-CoV-2 $(n=4)$. The antiviral activity was measured by plaque reduction assay. ** indicates $\mathrm{P}<0.01$ when compared with $\mathrm{P} 16$. $\mathrm{P}$ values were calculated by the two-tailed Student's $\mathrm{t}$ test. Data are presented as mean \pm SD of independent biological samples. 
Fig. 4

Endosomal acidification inhibitors against viruses in animals and ex vivo human lungs. (A) P16 inhibited $A(H 1 N 1)$ virus replication in mouse lungs $(n=5)$ at day 2 post infection. (B) The survivals of $A(H 1 N 1)-$ infected mice intranasally treated by P16 (50 $\mu \mathrm{g} /$ dose, $n=9)$, zanamivir (Zana, $40 \mu \mathrm{g} / \mathrm{dose}, \mathrm{n}=5)$ or PBS (Mock, $n=9$ ) at 6 h post infection with two more doses in the following day. $P$ value was calculated by Gehan-Breslow-Wilcoxon test. (C) Antiviral efficiency of P16 against parent H1N1 (P0, n = 3), 15-passaged virus $(P 15, n=3)$ and 20-passaged virus (P20, $n=3)$. Viral RNA copies in cell supernatants were measured at $18 \mathrm{~h}$ post infection and normalized to untreated virus (0). (D) P16 and chloroquine (Chl, $2 \mathrm{mg} \mathrm{kg}^{-1}$ ) inhibited SARS-CoV-2 replication in hamster lungs at day 2 post infection $(n=4)$. (E) Chloroquine $(2$ mg $\left.\mathrm{kg}^{-1}\right)$ inhibited $\mathrm{A}(\mathrm{H} 1 \mathrm{~N} 1)$ virus replication in mouse lungs at day 2 post infection $(\mathrm{n}=8)$. Drugs were intranasally inoculated to animals at $6 \mathrm{~h}$ post infection with two more doses in the following day. (F) Chloroquine was more effectively inhibit viral replication during viral infection $(n=4)$. Chloroquine was added to cells at the indicated time points. Viral RNA copies in supernatants were measured at $24 \mathrm{~h}$ post infection. * indicates $\mathrm{P}<0.05$ and ** indicates $\mathrm{P}<0.01$ when compared with 'Oh'. (G-H) Atomization inhalation of chloroquine (50 mg/mouse, one dose) inhibited SARS-CoV ( $n=4)$ and A(H1N1) virus ( $n=8)$ replication in mouse lungs at day 1 post infection. (I) Chloroquine $\left(5 \mu \mathrm{g} \mathrm{ml}^{-1}\right)$ significantly inhibited SARS-CoV-2 replication in ex vivo human lung tissues $(n=4)$. Viral RNA copies in supernatants were measured at $60 \mathrm{~h}$ post infection. (J) Schematic figure of functional chloroquine against $\mathrm{pH}$-dependent virus. * indicates $P<0.05$ and ** indicates $P<0.01$ when compared with mock. $P$ values were calculated by the two-tailed Student's t test. Data are presented as mean \pm SD of independent biological samples.

\section{Figures}


A

\begin{tabular}{lcc}
\hline Peptide & Sequence & Charge \\
\hline Urumin & IPLRGAFINGRWDSQCHRFSNGAIACA & +2 \\
U1 & IPLRGAFINGRWD & +1 \\
U2 & FINGRWDSQCHRFS & +1 \\
U3 & WDSQCHRFSNGAIACA & 0 \\
U4 & FINGRWDSQCHRFSNGAIACA & +1 \\
U5 & IPLRGAFINGRWDSQCHRFS & +2 \\
P16 & RGAHIKGRWKSRCHRF & +6.1 \\
\hline
\end{tabular}

B

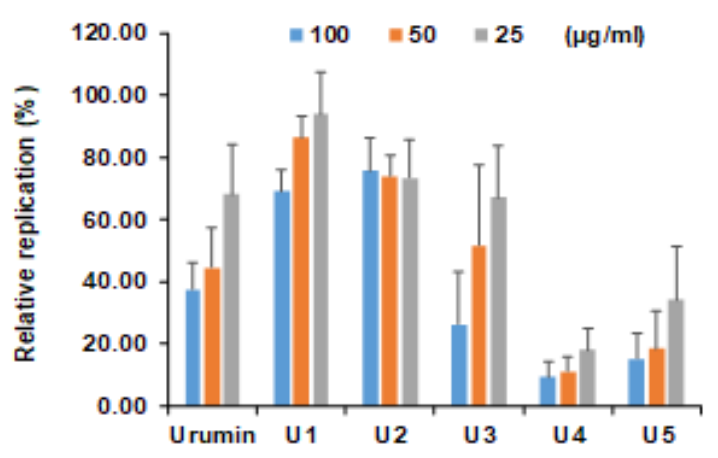

$\mathbf{F}$
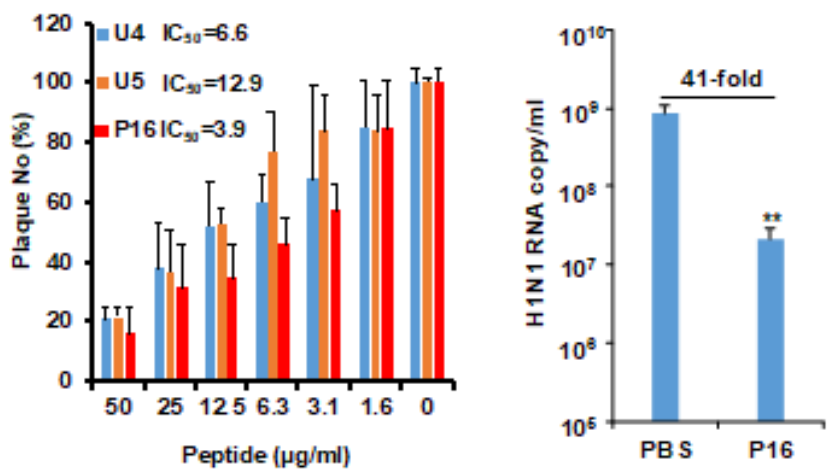

$\mathbf{E}$
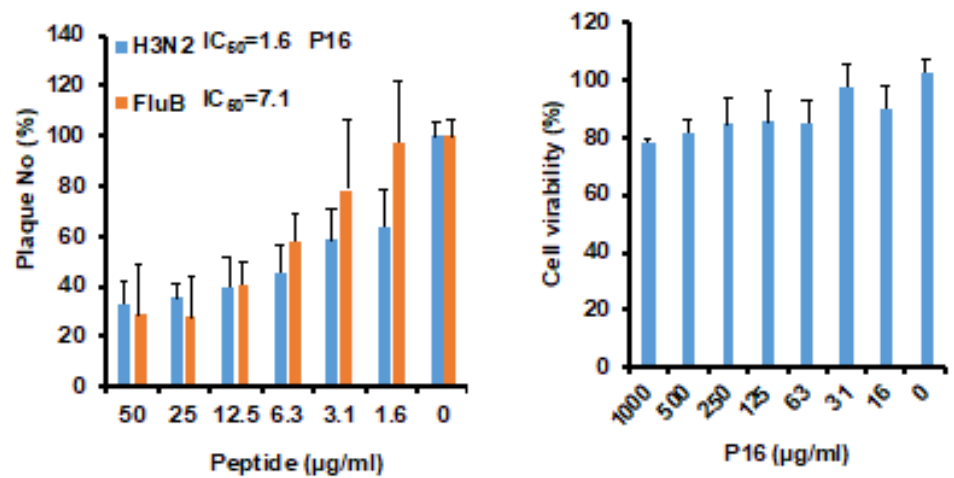

\section{Figure 1}

Identification of short basic peptide against influenza A and B viruses. (A) Peptide sequences and their positive charges calculated by PepCalc of InnovaGen related to $\mathrm{pH}$ 7.0. (B) The antiviral activity of peptides against $A(H 1 N 1)$ virus $(n=3)$. Virus was pretreated by peptides with the indicated concentrations for infection in MDCK cells. Viral RNA copies in cell lysate were measured by RT-qPCR at $5 \mathrm{~h}$ post infection. Relative replication is defined as the percentage of RNA copies of treated samples relative to those of untreated virus. (C) Antiviral activity of peptides against $A(\mathrm{H} 1 \mathrm{~N} 1)$ virus were measured by plaque reduction assay ( $n=3)$. (D) Antiviral activity of P16 against $A(H 1 N 1)$ virus were measured by RT-qPCR to test the viral RNA copies in supernatants of $18 \mathrm{~h}$ post infection $(n=3)$. ** indicates $P<0.01$. $P$ value was calculated by the two-tailed Student's $t$ test when compared with PBS. (E) Antiviral viral activities of P16 against $A(H 3 N 2)$ and influenza $B(F l u B)$ viruses were measured by plaque reduction assay $(n=4)$. ( $F)$ Cytotoxicity of P16 in MDCK cells $(n=3)$. Data are presented as mean \pm SD of independent biological samples. 
A

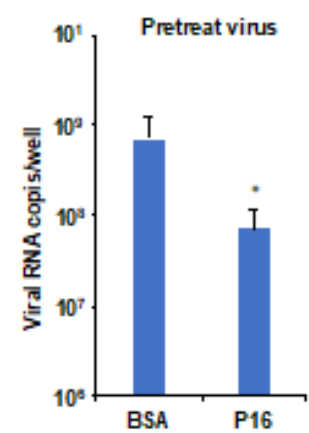

B

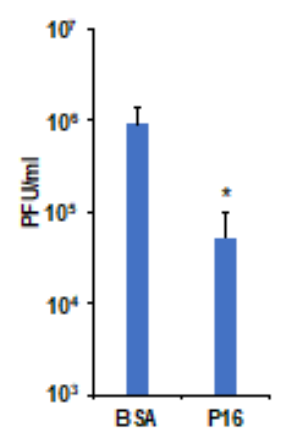

C

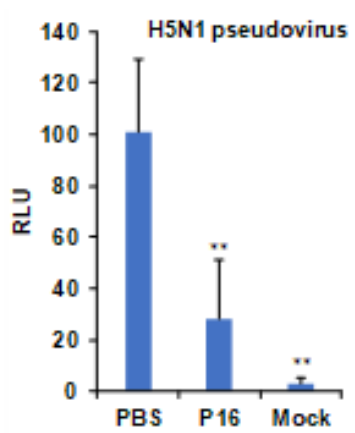

D

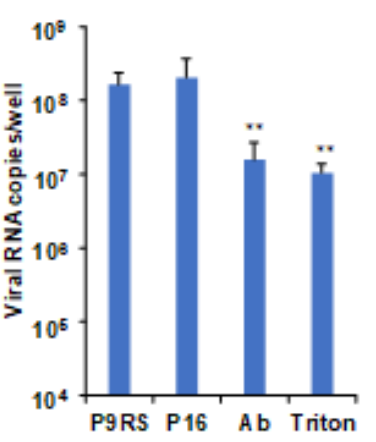

E

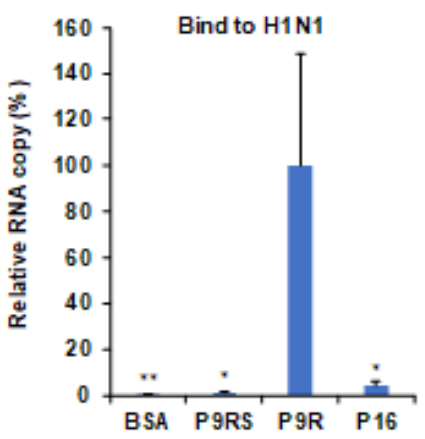

$\mathbf{F}$

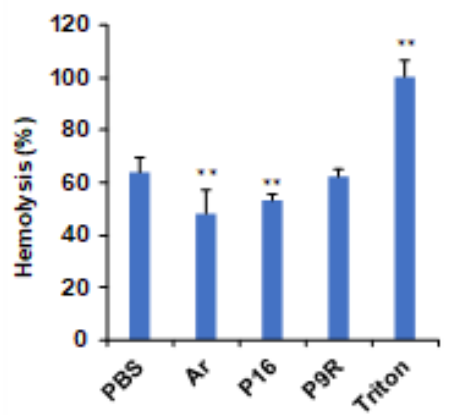

G
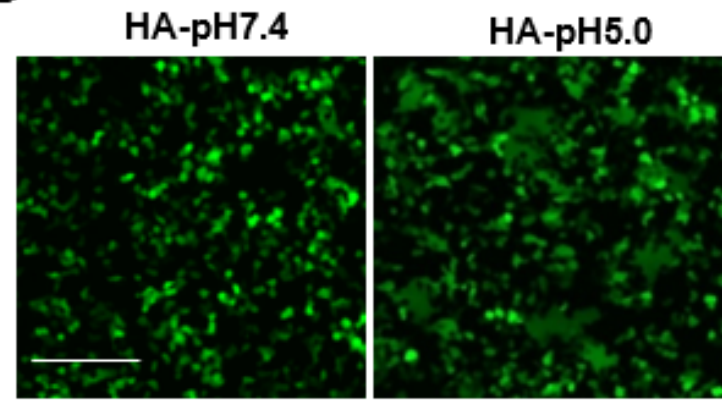

HA-pH5.0+P16

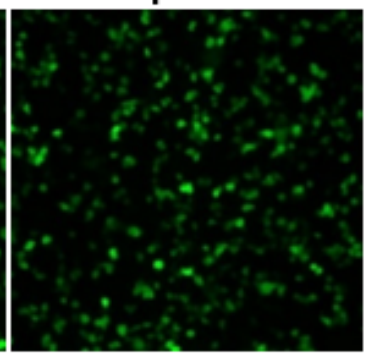

H

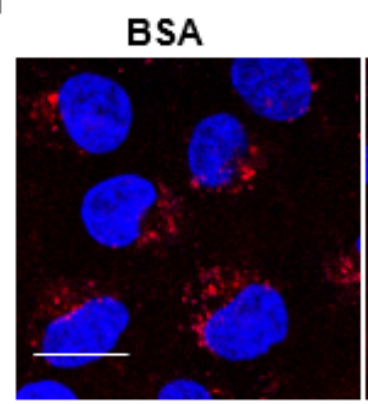

P16

BA1
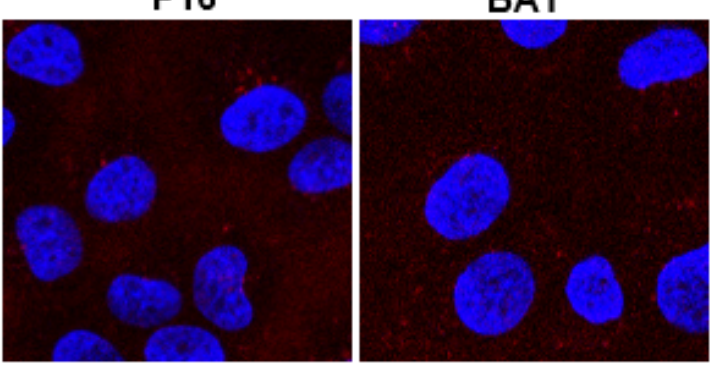

\section{Figure 2}

Identification of short basic peptide against influenza A and B viruses. (A) Peptide sequences and their positive charges calculated by PepCalc of InnovaGen related to $\mathrm{pH}$ 7.0. (B) The antiviral activity of peptides against $A(H 1 N 1)$ virus $(n=3)$. Virus was pretreated by peptides with the indicated concentrations for infection in MDCK cells. Viral RNA copies in cell lysate were measured by RT-qPCR at $5 \mathrm{~h}$ post infection. Relative replication is defined as the percentage of RNA copies of treated samples relative to 
those of untreated virus. (C) Antiviral activity of peptides against $A(H 1 N 1)$ virus were measured by plaque reduction assay $(n=3)$. (D) Antiviral activity of P16 against $A(H 1 N 1)$ virus were measured by RT-qPCR to test the viral RNA copies in supernatants of $18 \mathrm{~h}$ post infection $(n=3)$. ** indicates $P<0.01$. $P$ value was calculated by the two-tailed Student's $t$ test when compared with PBS. (E) Antiviral viral activities of P16 against $A(H 3 N 2)$ and influenza $B(F l u B)$ viruses were measured by plaque reduction assay $(n=4)$. ( $F)$ Cytotoxicity of P16 in MDCK cells $(n=3)$. Data are presented as mean \pm SD of independent biological samples.

A

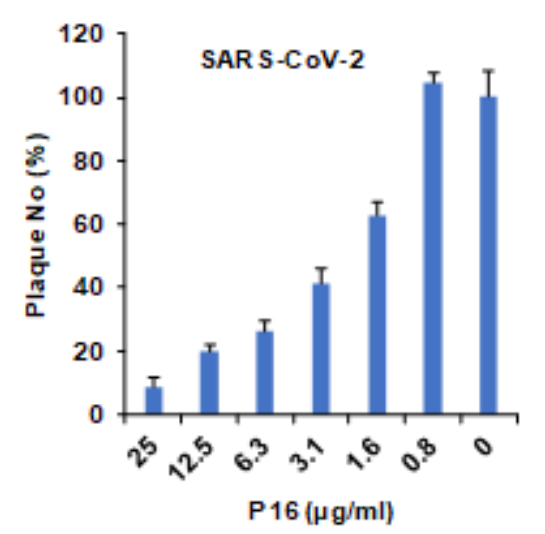

B

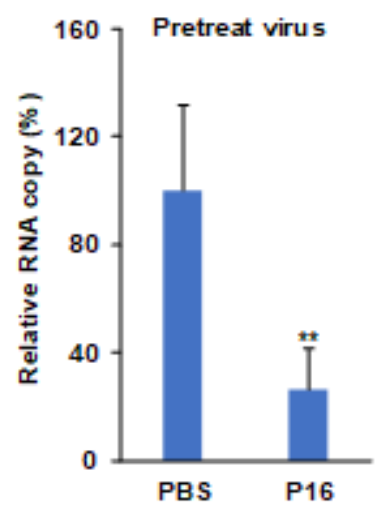

C

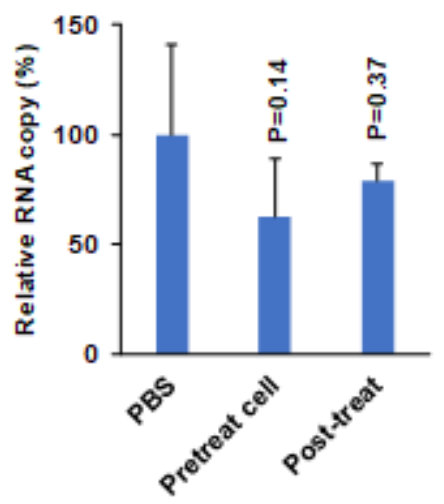

D
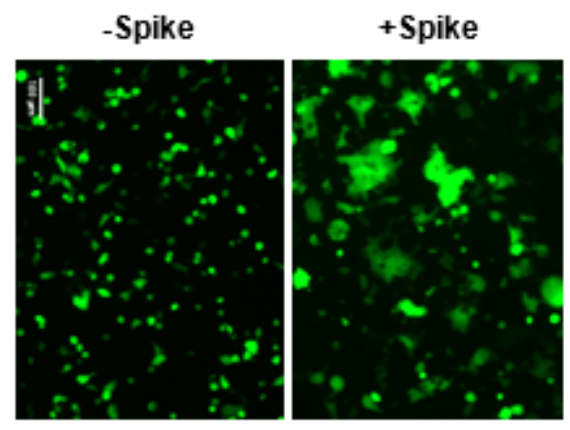

+Spike+P16

+Spike+U5
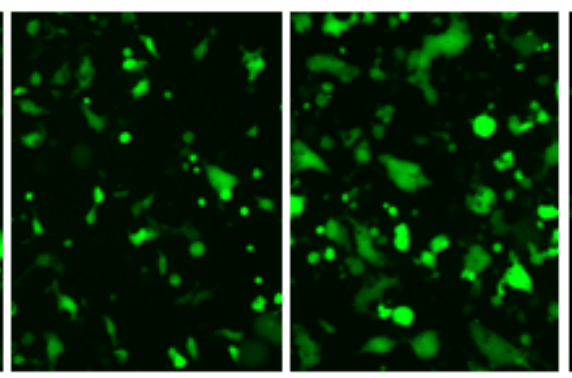

+Spike+BA1

E

\section{F}

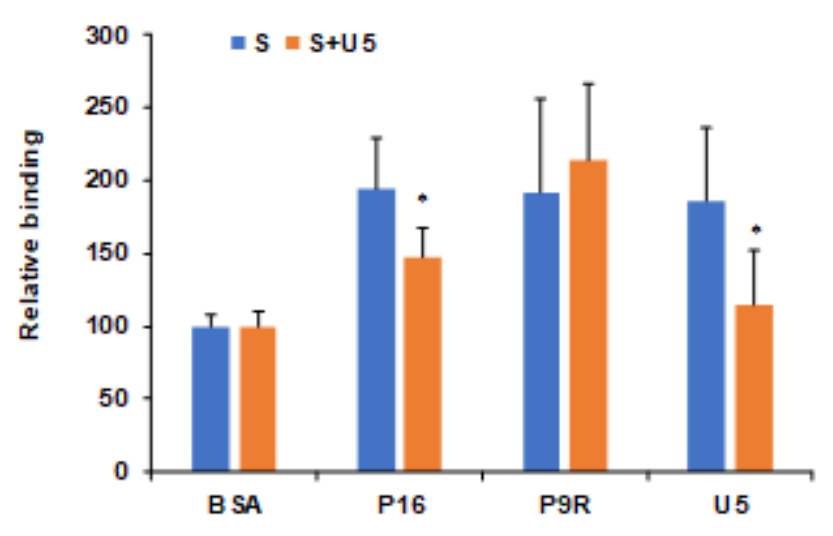


P16 inhibited SARS-CoV-2 infection. (A) Antiviral activity of P16 against SARS-CoV-2 in Vero-E6 cells $(\mathrm{n}=3)$. SARS-CoV-2 was premixed with P16 for cell infection. Plaque No (\%) was plaque No of P16-treated virus normalized to plaque No of untreated virus. (B) SARS-CoV-2 was pretreated by P16 and then infected cells for $1 \mathrm{~h}$. Viral RNA copies in cell lysates were measured by RT-qPCR at $8 \mathrm{~h}$ post infection $(n=5)$. (C) Cells were pretreated by P16 (Pretreat cell) before viral infection and P16 was added to cells at $1 \mathrm{~h}$ post infection (Post-treat). At 8h post infection, viral RNA copies in cell lysates were measured by RTqPCR $(n=3)$. ** indicates $P<0.01$ when compared with PBS. (D) P16 could inhibit spike-ACE2 mediated cell fusion. The $293 \mathrm{~T}$ cells were transfected with pGFP+spike or pACE2, separately. At $24 \mathrm{~h}$ later, two transfected cells were co-cultured with the addition of drug P16 (250 $\mu \mathrm{g} \mathrm{ml}-1), \mathrm{U} 5(250 \mu \mathrm{g} \mathrm{ml}-1)$ and bafilomycin A1(BA1, $50 \mathrm{nM}$ ). The fusion pictures were taken at $4 \mathrm{~h}$ post co-culture. Cells with GFP-spike only were served as the no-fusion control. Scale bar $=100 \mu \mathrm{m}$. Experiments were repeated twice. (E) P16 could bind to $S$ protein and U5 could block P16 binding to S protein $(n=4)$. S protein of SARS-CoV-2 and S treated by U5 (S+U5) were added to ELISA plate for binding to peptides coated on ELISA plate. * indicates $P<0.05$ when compared with untreated $S$. (F) U5 showed weaker antiviral activity than that of P16 against SARS-CoV-2 $(n=4)$. The antiviral activity was measured by plaque reduction assay. $* \star$ indicates $P<0.01$ when compared with P16. P values were calculated by the two-tailed Student's $t$ test. Data are presented as mean $\pm S D$ of independent biological samples. 
A

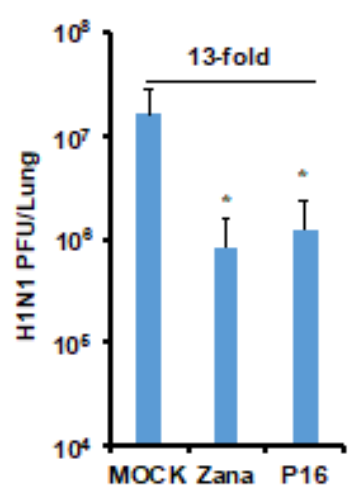

D

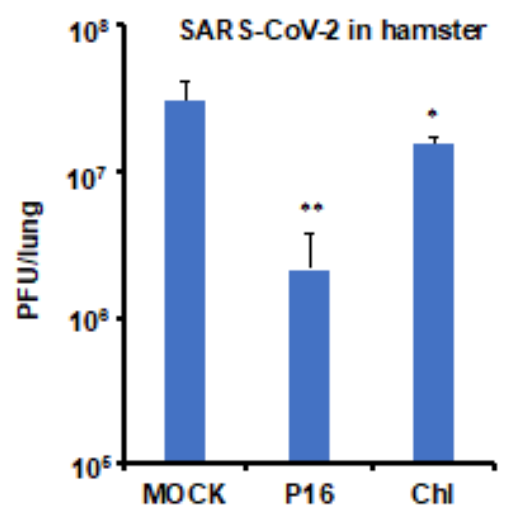

G

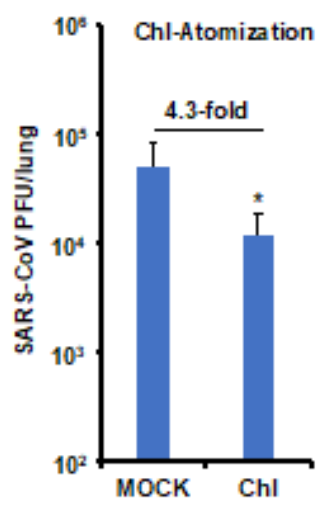

B

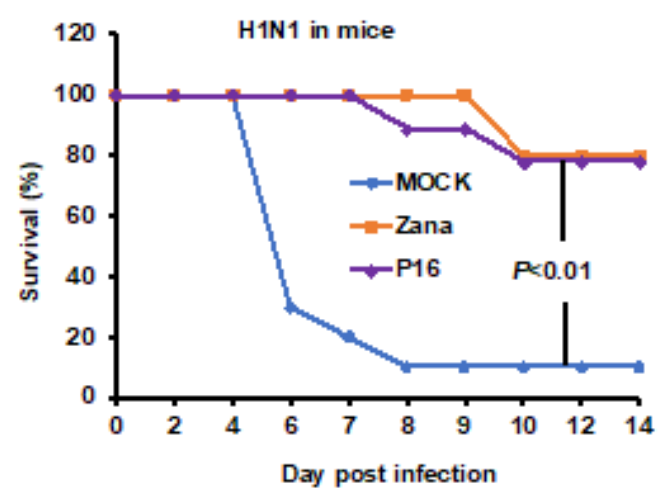

$\mathbf{E}$

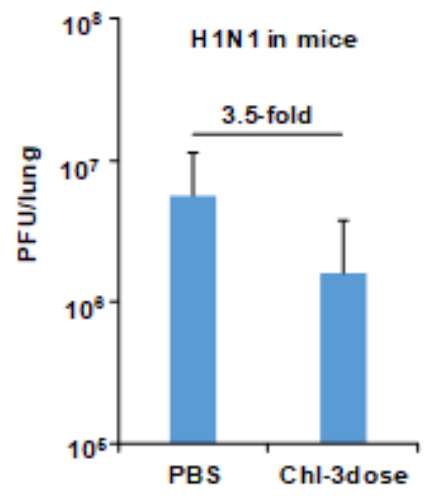

$\mathbf{F}$

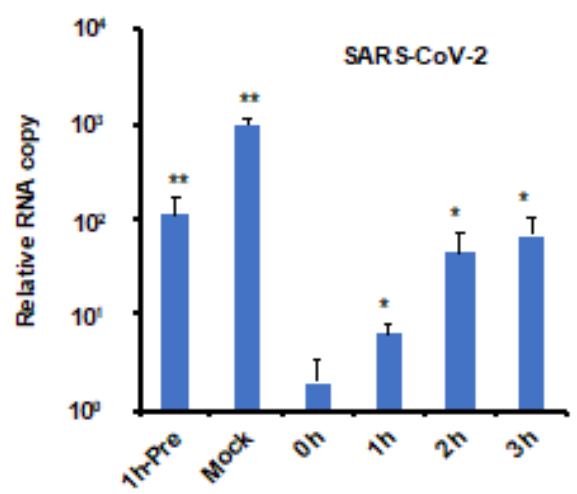

$\mathbf{J}$

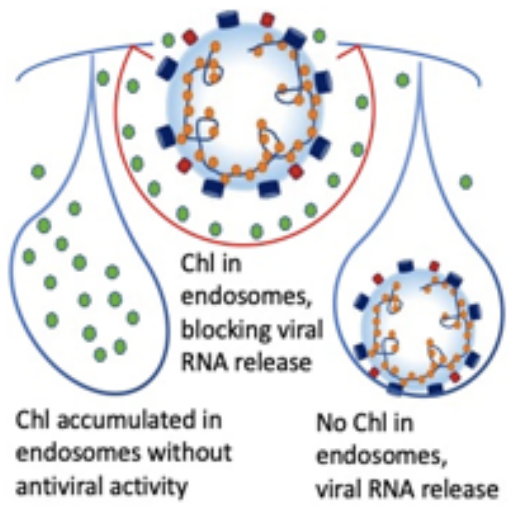

Figure 4

Endosomal acidification inhibitors against viruses in animals and ex vivo human lungs. (A) P16 inhibited $A(H 1 N 1)$ virus replication in mouse lungs $(n=5)$ at day 2 post infection. (B) The survivals of $A(H 1 N 1)$ infected mice intranasally treated by P16 (50 $\mu \mathrm{g} /$ dose, $\mathrm{n}=9$ ), zanamivir (Zana, $40 \mu \mathrm{g} / \mathrm{dose}, \mathrm{n}=5$ ) or PBS (Mock, $n=9$ ) at 6 h post infection with two more doses in the following day. $P$ value was calculated by Gehan-Breslow-Wilcoxon test. (C) Antiviral efficiency of P16 against parent H1N1 (PO, n=3), 15-passaged 
virus $(P 15, n=3)$ and 20-passaged virus $(P 20, n=3)$. Viral RNA copies in cell supernatants were measured at $18 \mathrm{~h}$ post infection and normalized to untreated virus (0). (D) P16 and chloroquine (Chl, $2 \mathrm{mg} \mathrm{kg}-1$ ) inhibited SARS-CoV-2 replication in hamster lungs at day 2 post infection $(n=4)$. ( $E)$ Chloroquine $(2 \mathrm{mg} \mathrm{kg}-$ $1)$ inhibited $A(H 1 N 1)$ virus replication in mouse lungs at day 2 post infection $(n=8)$. Drugs were intranasally inoculated to animals at $6 \mathrm{~h}$ post infection with two more doses in the following day. $(\mathrm{F})$ Chloroquine was more effectively inhibit viral replication during viral infection $(n=4)$. Chloroquine was added to cells at the indicated time points. Viral RNA copies in supernatants were measured at 24h post infection. * indicates $\mathrm{P}<0.05$ and ** indicates $\mathrm{P}<0.01$ when compared with ' $\mathrm{Oh}$ '. (G-H) Atomization inhalation of chloroquine (50 mg/mouse, one dose) inhibited SARS-CoV ( $n=4)$ and A(H1N1) virus ( $n=8)$ replication in mouse lungs at day 1 post infection. (I) Chloroquine $(5 \mu \mathrm{g} \mathrm{ml}-1)$ significantly inhibited SARSCoV-2 replication in ex vivo human lung tissues $(n=4)$. Viral RNA copies in supernatants were measured at $60 \mathrm{~h}$ post infection. $(\mathrm{J})$ Schematic figure of functional chloroquine against $\mathrm{pH}$-dependent virus. * indicates $\mathrm{P}<0.05$ and $* *$ indicates $\mathrm{P}<0.01$ when compared with mock. $\mathrm{P}$ values were calculated by the two-tailed Student's $t$ test. Data are presented as mean $\pm S D$ of independent biological samples.

\section{Supplementary Files}

This is a list of supplementary files associated with this preprint. Click to download.

- Supplementarylnformation20210211.docx 